\title{
La clase obrera y su relación con el territorio en Espańa durante el franquismo. Análisis de tres modelos de organización contemporáneos
}

Ricardo Carcelén-González. Universidad Politécnica de Cartagena, Cartagena, España.

RESUMEN | La necesidad de organizar en el territorio a la clase obrera en la España de mediados del siglo xx daría lugar a un intenso periodo de investigación arquitectónica y urbana en todos aquellos contextos en los que tendría lugar el fenómeno: en la periferia de la ciudad industrial, en el entorno rural y en la menos estudiada orilla litoral. Para dar a conocer las "ciudades de vacaciones" de Educación y Descanso como sistema organizativo del reposo obrero, se realiza un análisis comparativo con otros dos modelos contemporáneos, los "poblados dirigidos" y los "pueblos de colonización”, que, pese a sus diferentes planteamientos, abordarían una similar problemática. Para ello, se han estudiado diversos parámetros cuantitativos de densidad y usos del suelo comunes a los tres modelos. El texto revela, como conclusiones, las particularidades de un modelo organizativo cuyas características formales se verán definitivamente influidas por su específico destino.

PALABRAS CLAVE | asentamientos humanos, historia urbana, relación campo-ciudad.

ABSTRACT | The need to organize the working class in mid-twentieth century Spain would lead to an intense period of architectural and urban research in all those contexts in which the phenomenon would take place: on the periphery of the industrial city, in the rural environment and in the less studied shoreline. To publicize the "ciudades de vacaciones" (holiday cities) promoted by the Spanish union organization "Educación y Descanso" as an organized system for workers rest, a comparative analysis is conducted with two other contemporary models, both "poblados dirigidos" and "pueblos de colonización," which despite their different approaches would address a similar problem. For this, a series of quantitative parameters of density and land uses common to the three models have been studied. As conclusions, the text reveals the particularities of an organizational model with formal characteristics that will be definitively influenced by its specific destination.

KEYWORDS | human settlements, urban history, countryside-city relationship. 


\section{Análisis del contexto}

Los orígenes de la relación entre ciudad y clase obrera en España han de buscarse, según autores como el especialista en historia urbana Oyón (2002), en el periodo conocido como de entreguerras, entre los ańos veinte y treinta. Al respecto seńala que "en la primera mitad del siglo xx quedó ya definitivamente consolidada en torno a la ciudad, la moderna clase trabajadora, masiva y definitivamente proletarizada” (p. 11). Más adelante, en el mismo texto, nos presenta la interpretación que Cronin ${ }^{1}$ había hecho de la relación entre vida obrera y formas urbanas: "La primera característica de la nueva distribución obrera en la ciudad -señala Oyón (p. 22)sería la de su novedad en el crecimiento urbano. Esos barrios que se dibujaron en el mapa de la ciudad se habrían formado a causa de la descentralización de la nueva industria y de la residencia producida por los nuevos medios de transporte de masas, fundamentalmente el tranvía eléctrico".

Este desplazamiento de la industria a la periferia de las ciudades -en definitiva, aquello a lo que se refiere el término "descentralización"- arrastró tras de sí a los trabajadores, que optaron por establecer sus residencias en una situación próxima respecto de sus puestos de trabajo, lo que en cuestión de tiempo dio lugar a la formación de los nuevos barrios obreros, que constituyeron el germen de este fenómeno. En el presente trabajo, sin embargo, no interesan tanto sus orígenes, como las respuestas arquitectónicas y urbanísticas que a él se darían en la década de los años cincuenta. Fue en este contexto que paralelamente surgieron los llamados "poblados dirigidos", los "pueblos de colonización” y el tercero de los modelos, en el cual se centra el presente estudio comparativo: las "ciudades de vacaciones", impulsadas por Educación y Descanso, entidad dependiente de la Organización Sindical Española.

Afortunadamente, han sido numerosos los autores que en las últimas décadas se han interesado en la ampliación del conocimiento sobre la vivienda obrera, así como de su agrupación para la conformación de barrios o poblados, asentamientos autosuficientes en cierto grado estos últimos, destinados a la masiva clase trabajadora de mediados del siglo xx en nuestro país. Entre estos estudios, se distinguen aquellos que han abordado este tema en el complejo contexto de la ciudad industrial (emigración de trabajadores desde los núcleos rurales hacia las periferias industriales de las ciudades, en busca del trabajo que las grandes urbes en pleno proceso de industrialización ofrecían), y los que han mostrado su interés en el desarrollo del fenómeno obrero en el entorno rural (desplazamiento de trabajadores del campo a las nuevas extensiones de terreno de regadío en territorio rural, donde se desarrollarían los conocidos como "pueblos de colonización").

Atendiendo al primer grupo, Tatjer (2005) puso de manifiesto en su "estado de la cuestión sobre las estrategias y actuaciones de los diversos tipos de promotores de vivienda obrera de los siglos XIX y xx" lo fructífero que ha resultado este campo de trabajo en los últimos años, con estudios que han abarcado desde enfoques más

1 Referencia a J. E. Cronin, "Labor Insurgency and Class Formation: Comparative Perspectives on the Crisis of 1917-1920 in Europe", en J. E. Cronin y C. Siriani (eds.), Work, Community and Power. The Experience of Labor in Europe and America, 1900-1925 (Filadelfia: Temple University Press, 1983). [N. de E.]. 
generalistas hasta aquellos de alcance más específico. En ese sentido, son interesantes para este trabajo principalmente -entre otros- los análisis de autores como Fernández-Galiano, Isasi y Lopera (1989), Moya (1976, 1983), o Sambricio (2003), aproximaciones que, aun centrándose fundamentalmente en el fenómeno obrero acontecido en Madrid, han llegado a posicionarse como estudios de referencia en este campo.

En cuanto a los trabajos que engloban el segundo grupo, aquellos sobre la organización de la clase obrera en entornos rurales, también reconocemos como obras de referencia las desarrolladas en tono generalista por autores como Oyón (1985); o que emplean un enfoque más específico, como las investigaciones arquitectónicas de Centellas (2010) y Centellas, Ruiz y García-Pellicer (2009); o históricas, de Rabasco (2009).

Completan el espectro los trabajos realizados por el autor de este texto, que han permitido ampliar el conocimiento aportado por investigadores como Guerrero (2016), Sanz (2001) o Tomillo (2014) sobre el poco conocido modelo de organización de las clases trabajadoras puesto en práctica en las ciudades de vacaciones -también denominadas como residenciales o sindicales- promovidas en España por la Obra Sindical Educación y Descanso contemporáneamente a los dos modelos señalados anteriormente (Carcelén, 2017).

\section{Modelos de organización de las clases obreras en el territorio: metodología y datos}

A continuación, se analiza cada uno de los sistemas de organización que se presentaban en el punto anterior. La elección de tres casos de estudio -poblados dirigidos, pueblos de colonización y ciudades de vacaciones- responde a la intención del trabajo de contraponer estos modelos tan distintos en planteamiento y destino $y$, sin embargo, producidos al mismo tiempo por un mismo gobierno franquista; y además dirigidos, en términos generales, a una misma población. Con el fin de establecer unos datos comunes que permitan el posterior análisis comparativo entre los distintos modelos, se ha seguido la metodología ya empleada por Moya (1976; 1983, p. 94), cuando con eficacia atiende a las "características cuantitativas" de densidad y usos del suelo para realizar la comparación entre sí de los barrios obreros de promoción oficial de Madrid, extendiendo en nuestro caso el método a los modelos organizativos contemporáneos seńalados. Por ello, se han seleccionado los siguientes parámetros como objetos de análisis: densidad de los asentamientos; porcentajes de ocupación de viviendas y de espacios libres de uso privado (patios, porches, terrazas, etcétera); ocupación de equipamientos públicos; ocupación de viario; y, finalmente, ocupación de los espacios libres de uso público, de vacío.

Finalmente, dentro de cada uno de los contextos referidos, se han seleccionado distintos casos de estudio atendiendo a los siguientes criterios:

a. Periferia de la ciudad industrial: a pesar de que el fenómeno de construcción de nuevos poblados de vivienda obrera es en este periodo extensivo a la totalidad del territorio nacional, es sin duda en Madrid donde mayor desarrollo 
y complejidad adquiriría como consecuencia de la ejecución de multitud de nuevos barrios y poblados que, como formula Sambricio (1999), reciben diferentes nomenclaturas según las características y función del tipo de asentamiento. Al respecto, se definen hasta cuatro nuevos tipos de poblados: poblados de absorción, poblados mínimos - posteriormente denominados unidades vecinales de absorción (UVA)-, poblados dirigidos y poblados agrícolas. De estos cuatro tipos de poblados, son los denominados como dirigidos (Entrevías, Canillas, Fuencarral, Orcasitas, Caño Roto, Manoteras y Almendrales) los que interesa diseccionar en este trabajo, dado que el objetivo principal de tales conjuntos sería la organización de un gran número de trabajadores recién llegados a la ciudad.

b. Entorno rural: a pesar de que en España se construyeron casi trescientos pueblos de colonización (Centellas, 2010) para organizar a las clases trabajadoras en el entorno rural, se ha optado por analizar dos de los casos de estudio más significativos y representativos, por su cercanía en escala al resto de casos de estudio del trabajo: el pueblo de Vegaviana, Cáceres (1956) y el pueblo de Cańada de Agra, Albacete (1962), ambos ideados por el reconocido arquitecto Fernández del Amo.

c. Orilla litoral: en España se ejecutaron durante el franquismo tan solo tres ciudades de vacaciones para organizar el descanso y las vacaciones de las clases medias trabajadoras. Así, se han analizado los parámetros seńalados en la Ciudad Residencial de Tarragona (1955-1957), en la Ciudad Sindical de Marbella, Málaga (1956-1962) y, finalmente, en la Ciudad Residencial de Perlora, Oviedo (1956-1967).

El objetivo principal de este trabajo consiste, entonces, en analizar la respuesta territorial que en estos tres diferentes ámbitos darían los arquitectos del momento a una problemática que, salvando las distancias en el contexto, ofrecía similar formulación de partida: la necesidad de organizar a las masas obreras en el territorio.

Nuevos barrios para las clases trabajadoras en la periferia de la ciudad industrial: los "poblados dirigidos"

La construcción de estos asentamientos se ajusta, tal y como apunta López Díaz (2002), a las directrices de lo que se denominó Política de Poblados (1954-1955), que englobaba las nuevas legislaciones en materia de vivienda (de renta reducida, de renta mínima y de tipo social), el primer Plan de Vivienda Nacional del Instituto Nacional de Vivienda (Inv) y el primer Plan Sindical de la Obra Sindical del Hogar (osH), que proponía un desarrollo en cuatro etapas, de las cuales tan solo se pusieron finalmente en práctica las dos primeras: la creación de una serie de poblados de absorción y, posteriormente, la ejecución de otros tantos poblados de tipo dirigido. El planteamiento original contemplaba una tercera y cuarta fase, con el diseño de "Nuevos núcleos urbanos", actuación de categoría superior a los poblados dirigidos, y de los "Barrios-tipo", creación de una estructura completa de viviendas y servicios con una cierta entidad. 
Finalizada la primera de las fases, con la ejecución de ocho poblados de absorción-Canillas, San Fermín, Villaverde, Pan Bendito, Zofio, Caño Roto, Fuencarral A y Fuencarral B-, se procedió al desarrollo de la segunda fase de la Política de Poblados, el correspondiente a la ejecución de los poblados dirigidos. Para llevar a cabo la materialización de este ambicioso programa se recurrió a un equipo de jóvenes arquitectos (Oiza, Romany, Leoz, Molezún, Corrales, Íniguez, Vázquez de Castro, etcétera) -Fernández Galiano (1989) se referirá a ellos como la "generación de los poblados"-, obviamente conocedores de la tendencia racionalista europea gracias a sus estudios todavía recientes, sus viajes al extranjero y el paulatino acceso a publicaciones de obras extranjeras en revistas foráneas o a través de las cada vez más frecuentes referencias internacionales en las revistas españolas. La Comisaría de Ordenación Urbana (coum) depositó en estos arquitectos, nada comprometidos con la ideología arquitectónica imperante hasta el momento, confianza ciega para dar forma a un primer grupo de poblados dirigidos, encargo que supuso, para estos profesionales, una posibilidad sin precedentes en cuanto a ensayo, investigación y propuesta de una serie de actuaciones bien distintas de cuantas se habían llevado a cabo en España hasta la fecha; y que para el racionalismo madrileño significaría la incorporación por fin de las directrices marcadas por el Movimiento Moderno (Esteban, 1999; Moya, 1997).

El primer poblado dirigido que se construyó en Madrid fue el de Entrevías, en el año 1956, diseñado por Francisco J. Sáenz de Oiza, en equipo con los arquitectos Jaime Alvear Criado y Manuel Sierra Nava. A este conjunto le siguieron los poblados dirigidos de Canillas, Fuencarral, Caño Roto y Orcasitas (figura 1). Un año después, en 1957, se puso en marcha el poblado dirigido de Manoteras; y, finalmente en 1959, el poblado dirigido de Almendrales, el último conjunto de un grupo que compartía tanto estética arquitectónica como características constructivas (López Díaz, 2002).

En su tesis doctoral, Moya (1976) realiza un profundo estudio de los barrios de promoción oficial ejecutados en Madrid, aportando datos y llegando a valiosas conclusiones de gran interés para este trabajo (figura 2). El autor analiza las diferentes etapas de construcción de este tipo de conjuntos, recogiendo la información relativa a la década que nos afecta, la de los años cincuenta -fundamentalmente a partir de la segunda mitad del decenio-, periodo en el que, además, se ejecuta el grueso de poblados (un 56\% del total de las promociones). Moya subraya cómo los poblados obreros de este periodo poseen rasgos característicos que permiten diferenciarlos con facilidad del resto de actuaciones de otras etapas. Así, lo más usual es que en los poblados de esta década se alternen, sobre una base reticulada, bloques abiertos en altura de cuatro o cinco plantas con viviendas unifamiliares en hilera y con patio-jardín, reproduciendo un esquema al que Isasi (1989), entre otros autores, denominarían con el término inglés mixed development.

Así, cinco de los siete poblados dirigidos citados se ajustan fielmente a un esquema mixto en el que conviven bloques en altura y viviendas unifamiliares, generalmente en dos alturas; a saber: Canillas, Fuencarral, Caño Roto, Orcasitas y Manoteras. Los dos poblados que excepcionalmente reniegan del esquema mixto son, casualmente, el primero y el último, cronológicamente hablando. Entrevías, el primer poblado en 
ejecutarse, se ajusta a un esquema en el que exclusivamente se construyen viviendas bajas, que se agrupan conformando racimos cartesianos de viviendas -plataformas de geometría rectangular con seis piezas, cinco de ellas ocupadas por dobles peines de viviendas en hilera y la sexta vacía de edificación para generar espacios libres en la parcela-, ancladas a una retícula viaria que deja espacios abiertos. En el otro extremo se encuentra el poblado de Almendrales, en el que tan solo se construyen bloques de viviendas de cinco alturas. En cualquier caso, un estudio más global de este tipo de poblados efectivamente confirma la cadencia señalada por Moya. Si atendemos a las cifras de densidades de los diferentes conjuntos -Entrevías (102,12 viv/ha), Canillas (116,83 viv/ha), Fuencarral (114,6 viv/ha), Orcasitas (73,73 viv/ ha), Caño Roto (85,52 viv/ha), Manoteras (137,90 viv/ha) y Almendrales (125,27 viv/ha)-, se obtiene un valor medio de 107,99 viv/ha.

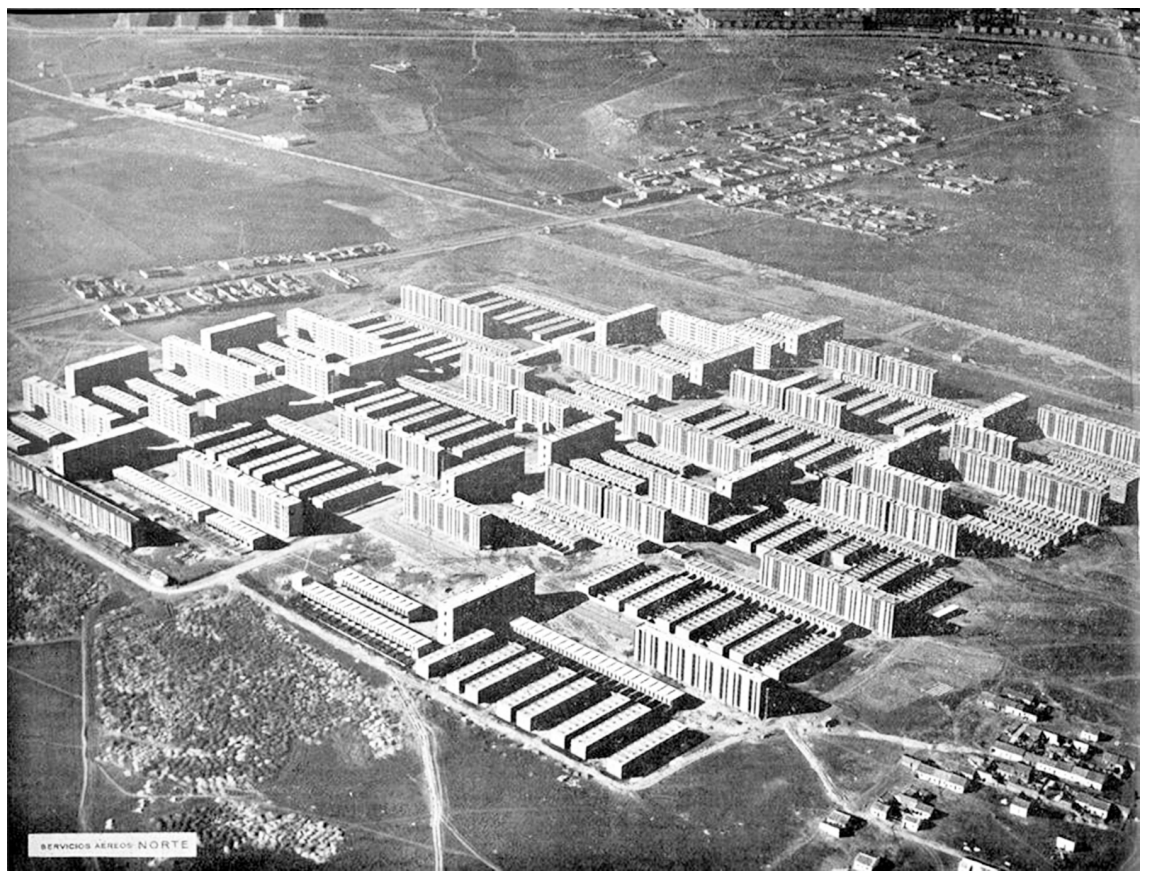

Figura I | Poblado dirigido de Orcasitas

FUENTE: SERVICIOS AÉREOS NORTE

Si se atiende a la repercusión de las viviendas en cuanto a ocupación del asentamiento, se obtiene un valor medio ligeramente superior al $25 \%$, resultando especialmente significativo el relativo a la ocupación de suelo libre de uso privado, que alcanza de media el 11,35\% del suelo total ocupado por el barrio. La importancia que adquieren estos espacios en los poblados dirigidos se debe a su papel de facilitar a las familias trabajadoras "el tránsito del mundo rural a la ciudad", entendiéndose el patio como un espacio para la realización de trabajos manuales y rurales (Guillem, 2014, p. 409). 


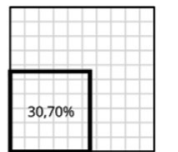

ENTREVIAS

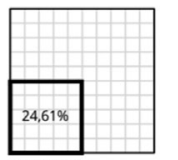

CANILLAS

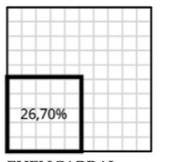

FUENCARRAL

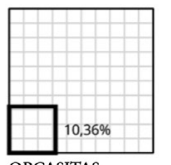

ORCASITAS

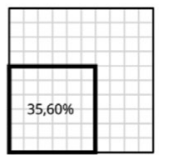

CAŃO ROTO

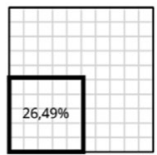

MANOTERAS

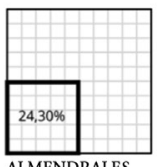

ALMENDRALES

Viviendas
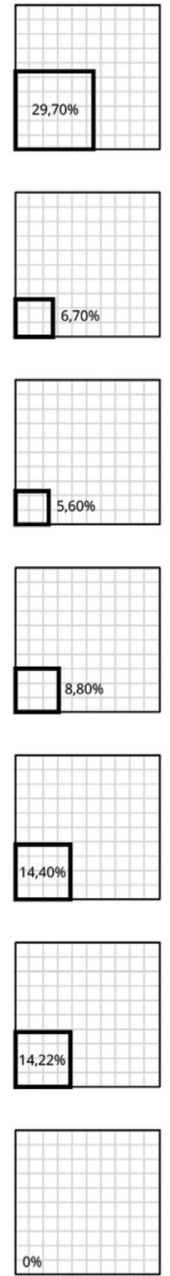

Espacio libre de uso privado
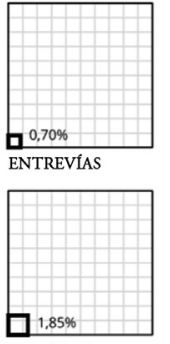

CANILLAS
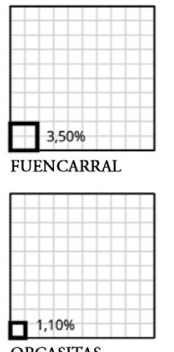

ORCASITAS

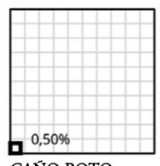

CAÑO ROTO
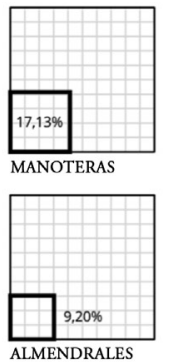

Equipamientos
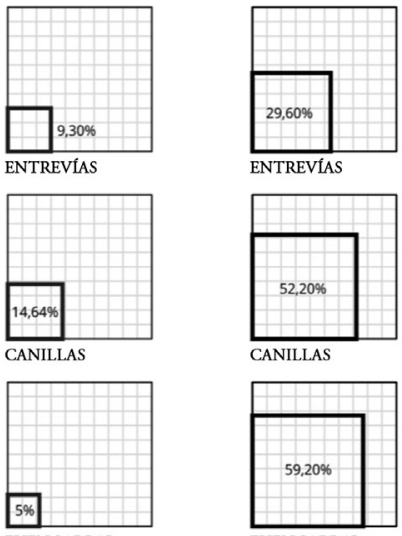

CANILLAS

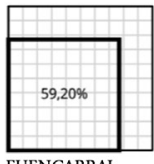

FUENCARRAL
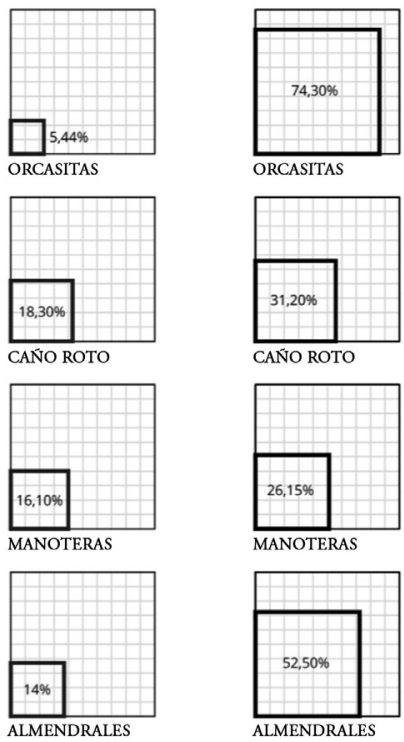

Viario

Espacio libre de uso público

FIGURA 2 | Porcentajes de ocupación en poblados dirigidos

FUENTE: ELABORACIÓN PROPIA CON BASE EN DATOS EXTRAÍDOS DE MOYA (I983)

El equipamiento colectivo de estos conjuntos se caracterizaba por ser escaso, con un valor medio de ocupación del 4,85\% del asentamiento. Este defecto se veía acentuado en la medida en que, además, no todo el equipamiento proyectado inicialmente llegaba a construirse (Moya, 1976), provocando que en ninguno de los casos se alcanzasen los estándares a los que el Plan Nacional de Vivienda obligaba. Los equipamientos que con más frecuencia se repiten en los poblados dirigidos, cuando existen, están constituidos por la iglesia; locales comerciales, generalmente en edificaciones de una planta, rodeando un espacio público que hace de plaza 
(dentro del programa comercial se incluye, en ocasiones, un dispensario destinado a prestar asistencia médica y farmacéutica); escuelas (o grupos escolares) y/o guarderías. Los dos primeros equipamientos colectivos de la relación anterior ocupan con carácter habitual posiciones centrales en el conjunto, relegándose a localizaciones más periféricas los dos últimos, que en ocasiones sirven a varios de estos barrios. Analizando el programa de equipamientos de los distintos poblados dirigidos, completarían la relación de equipamientos -aunque con menor frecuencia- un mercado o supermercado, un instituto de enseńanza media, un centro social o cultural, un centro sindical, edificios de oficinas y administración, y dependencias de correos y teléfonos. Moya (1976) pone de manifiesto cómo, con carácter general, en estos poblados obreros existe una fuerte carencia de equipamiento de reunión de la población del barrio, como serían centros sociales, centros de juventud, etcétera.

El viario en los poblados dirigidos se rige, con carácter general, por criterios de separación de las circulaciones rodadas y de las peatonales. El esquema habitual está basado en anillos perimetrales de ronda que intentan minimizar el acceso rodado hacia el interior de los asentamientos. Aquellos poblados en los que no se siguió este esquema, como Fuencarral, se han resentido de una solución defectuosa que propiciaba la penetración de los vehículos hacia el interior de los núcleos sin limitación alguna (Esteban, 1999). Esta misma problemática se detecta en el poblado de Orcasitas que, si bien en el planteamiento inicial resolvía estas cuestiones con un esquema de doble anillo perimetral con circulación peatonal interna, terminaría ajustándose a un esquema de libre acceso rodado al centro de los núcleos, siguiendo un esquema de reparto central. Paradójicamente, son los dos casos anteriores los que menor repercusión de viario rodado tienen en cuanto a ocupación de suelo en el asentamiento se refiere. Así, mientras poblados como Fuencarral y Orcasitas ven afectados apenas un $5 \%$ y un $5,44 \%$ de su suelo, respectivamente, el resto de poblados dirigidos se mantiene en una media de ocupación por el viario rodado por encima del $14 \%$, en una horquilla de valores que abarca desde el 9,3\% del poblado de Entrevías hasta el abultado 18,3\% de Caño Roto, según datos extraídos de Moya (1976).

En relación con los espacios libres de uso público, en los poblados dirigidos los arquitectos pudieron experimentar con diseños de menor densidad, obviamente viables por su situación en la periferia, con precios del suelo considerablemente más económicos. Sin embargo, como la distribución de las edificaciones del conjunto no se hacía siguiendo un programa claro y definido con antelación, los espacios libres abiertos resultantes carecen habitualmente de sentido. Estos vacíos cuentan con un factor de indefinición ineludible -la tónica habitual es que el espacio libre en los poblados dirigidos sea a la vez plaza, jardín y equipamiento deportivo-, pues ni en el momento en que se plantearon ni tampoco cuando se ejecutaron, se sabía cuál sería el uso concreto al que estaban destinados aquellos espacios, ni siquiera a quién correspondía la responsabilidad y el exigente mantenimiento correspondiente. Como denuncia Isasi (1989), "proyectados como un espacio de relación y de libertad e higiene, suelen constituir lo contrario" (p. 114). En la consideración del valor del espacio libre en estos asentamientos, encontramos planteamientos tan dispares como los de Canillas y Fuencarral, a pesar de que ambos ofrecen similares cifras en cuanto a ocupación de suelo destinado a espacio libre de uso público $(52,20 \%$ el primero, 
59,20\% el segundo). Así, mientras en el primero no se recurre a la típica ordenación de bloques aislados que en su configuración delimitan espacios libres entre ellos, pues de partida se han considerado estos como zonas infrautilizadas (Esteban, 1999), en el segundo se persigue fomentar dichos vacíos mediante un encadenamiento de los espacios libres que, apoyado en una amplia red de equipamiento comercial, ayuda a crear un ambiente que Moya (1983) define como "muy grato".

En lo que a espacio libre de uso público se refiere, se pone de manifiesto la mayor horquilla de valores de ocupación de suelo, no siendo posible determinar un posicionamiento claro de los arquitectos autores de este tipo de asentamientos frente a dicho parámetro. Así, el valor mínimo de vacíos de uso público se encuentra en el poblado de Manoteras, con un 26,15\% sobre el total del asentamiento, mientras que el poblado en el que más se apuesta en este tipo de uso del suelo es Orcasitas, donde la cifra de ocupación del espacio libre representa casi las tres cuartas partes del asentamiento, con un 74,3\% (Moya, 1976). Estos valores extremos nos dan un valor medio de liberación de suelo libre de uso público del 46,45\% en los poblados dirigidos; es decir, que en los nuevos núcleos residenciales para la clase trabajadora en la ciudad industrial se destina, como valor estimativo, la mitad de la superficie del asentamiento a espacios libres de uso público. Especial mención recibe en la bibliografía estudiada el poblado dirigido de Caño Roto que, si bien queda muy por debajo de la media estimada, con su 31,2\% de suelo destinado a espacio libre de uso público, este se ha trazado con una sensibilidad que se traduce en mejores espacios, mejor orientados y visualmente más agradables y proporcionados que el del resto de los poblados (Isasi, 1989). El éxito radica, sin duda, en el abandono de la idea de crear grandes extensiones ajardinadas entre las viviendas, que han resultado ser de discutida utilidad, optándose por crear espacios libres más reducidos, reproduciendo un esquema de callejuelas y placitas, con ajardinamiento que ahora sí puede ser cuidado por los residentes, quienes, de esta manera, comienzan a considerar estos espacios libres como propios (Esteban, 1999).

\section{Nuevos pueblos para las clases obreras en el entorno rural:}

los "pueblos de colonización”

También a mediados del siglo xx, el gobierno franquista promovió la construcción de casi trescientos pueblos de colonización dispersos por la amplitud del territorio español, cuya finalidad sería paliar los problemas que acuciaban al campo español. Al respecto, Centellas, Ruiz y García-Pellicer (2009) señalan el matiz filológico que distingue entre el término 'poblado' utilizado para los nuevos asentamientos de la ciudad industrial, que define una simple agrupación de viviendas pero sin ninguna vocación de autonomía, servicios comunes o personalidad jurídica; y el vocablo 'pueblo', que conlleva la planificación de una serie de equipamientos públicos esenciales para gozar de autonomía económica y administrativa, pero con el objetivo último de disponer de personalidad jurídica propia como municipio independiente. Para llevar a cabo tan ambiciosa empresa se creó, el 18 de octubre de 1939, el Instituto Nacional de Colonización (INC), y se elaboró en los años siguientes un marco legal que propiciaría el desarrollo de estos asentamientos de nueva creación (Centellas, 2010). 
El InC contó con un Servicio de Arquitectura liderado desde 1941 por el arquitecto José Tamés Alarcón, al mando de los arquitectos que asumirían la ejecución de los proyectos de los llamados pueblos de colonización -algunos de la talla de José Luis Fernández del Amo o de Alejandro de la Sota-. El equipo incluía un extenso cuerpo de técnicos conformado por veintiocho arquitectos funcionarios y otros casi ochenta que, ejerciendo la profesión liberalmente, recibirían estos encargos de forma directa. Estos arquitectos se enfrentaron de nuevo al difícil reto de construir una ciudad completa ex nibilo; pero, a diferencia de los poblados obreros de la ciudad industrial, en esta ocasión sí contaban con un amplio y detallado programa de partida, diseńado por el INC para su desarrollo, enfocado a que los colonos pudiesen disfrutar de los servicios adecuados y llevar una vida digna en todos sus aspectos: sociales, educativos, religiosos, sanitarios, etcétera.

Desde los inicios del Plan de Colonización se dio un intenso debate en relación con el tipo de asentamiento que se implementaría para este tipo de pueblos, y respecto de la conveniencia del modelo de viviendas agrupadas por sobre las diseminadas (viviendas aisladas en las propias parcelas de trabajo). Tamés (1948) enumeraba tanto las ventajas como los inconvenientes de uno y otro sistema, decantándose finalmente la balanza a favor de los asentamientos que conformaban pueblos o núcleos rurales. Se percibe así una clara tendencia que habría evolucionado desde los asentamientos dispersos, pasando por los de tipo semidisperso, progresivamente hacia soluciones concentradas, consecuencia al fin y al cabo de "la voluntad del INC por dotar a estos nuevos pueblos de aquellos servicios que asimilasen las condiciones de vida del campo a las de la ciudad, dotando de carácter urbano a estos nuevos asentamientos" (Oyón, 1985, p. 246) y de "la preocupación ideológica y social del INC [que] también les llevaba a priorizar la prestación de servicios religiosos, sanitarios y de enseñanza, así como potenciar las relaciones humanas entre colonos y sus familias" (Centellas, Ruiz \& García-Pellicer, 2009, p. 129).

La construcción de los casi trescientos pueblos de nueva planta resultó una empresa variada a la par que compleja. Los arquitectos que se enfrentaron a esta labor contaron con la máxima libertad a la hora de proyectar los nuevos trazados urbanísticos, pues las normativas reguladas por las circulares del INC se centraban en determinar los parámetros de dimensionamiento y superficie, pero nunca se entrometían en cuestiones de diseño. Esta singular circunstancia -en el caso de los poblados de absorción y dirigidos, las libertades eran menos, al existir una normativa de orden superior que atendía a estas cuestiones- convirtió los pueblos de colonización en un gran laboratorio de arquitectura y urbanismo, como señala Centellas (2010).

Los trazados evolucionaron desde los primeros esquemas de la década de los años cuarenta, que atendían a trazados orgánicos propios de una reinterpretación pintoresquista de las poblaciones tradicionales -según Rabasco (2009), "como si el propio sistema político tratara de anclarse en el propio territorio” (p. 76)-, hasta la convivencia en la década de los cincuenta de diseños racionalistas con trazados orgánicos como los de Vegaviana o Cañada de Agra (figura 3). Estos últimos trataban de amoldarse a la evolución de las modas arquitectónico-urbanísticas del momento, recurriendo a la forma irregular y al uso de calles curvas para una mayor variedad de perspectivas. 


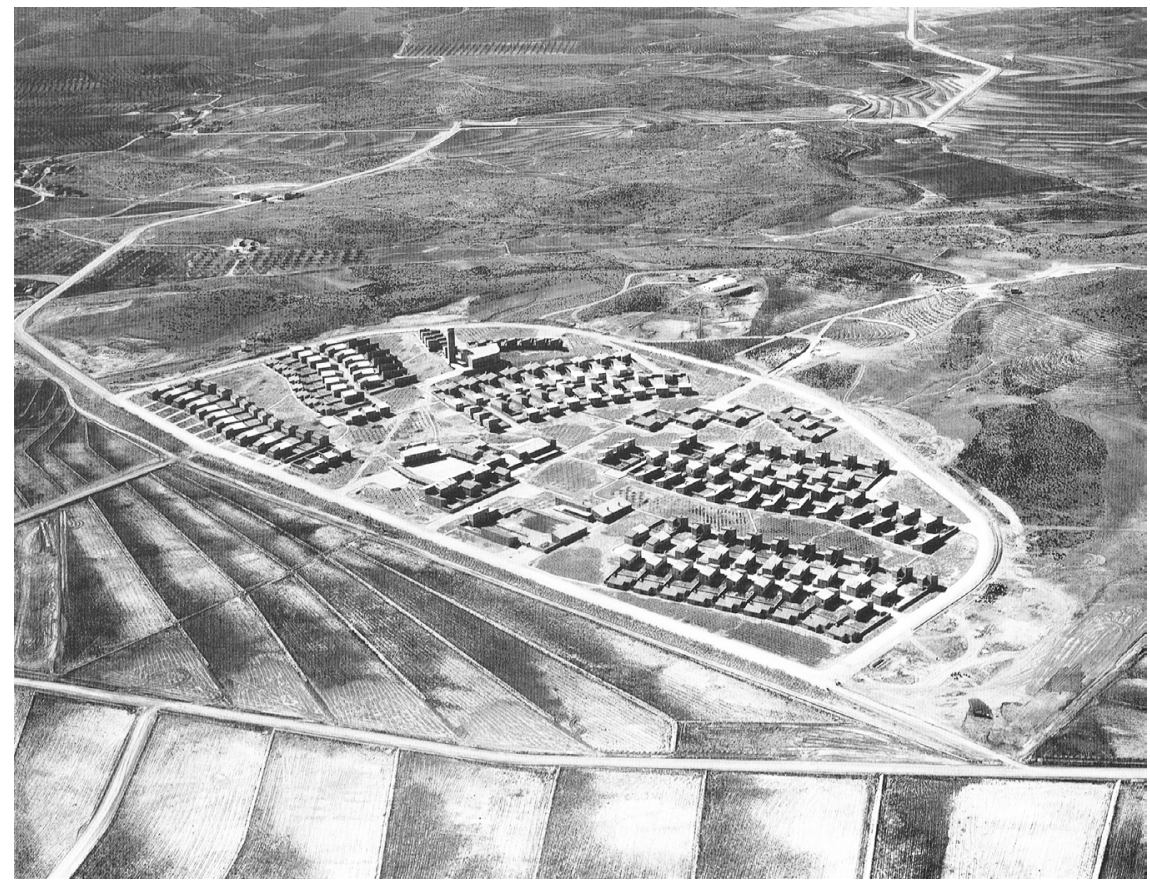

Figura 3 Pueblo de colonización de Cañada de Agra

FUENTE: CENTELLAS (2010)

A continuación, analizaremos los parámetros urbanos especificados para el caso de los pueblos de colonización (figura 4), los cuales se caracterizarían por resolverse siempre mediante esquemas de baja densidad. Centellas (2010, p. 131) apunta a una horquilla de valores de densidad en los conjuntos proyectados por Fernández del Amo, que oscila desde las 3,8 viv/ha en el Realengo hasta las 16,5 viv/ha en Villalba de Calatrava, con un valor medio de 8,4 viv/ha, muy por debajo de los datos seńalados para los poblados dirigidos.

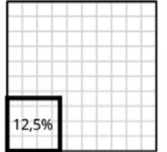

VEGAVIANA

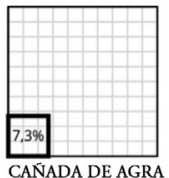

Viviendas
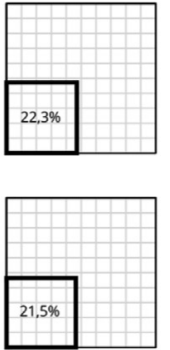

Espacio libre

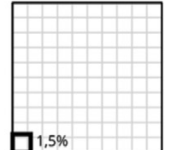

VEGAVIANA

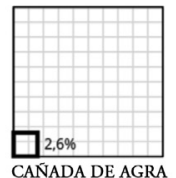

Equipamientos
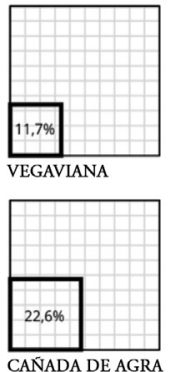

Viario

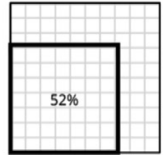

VEGAVIANA

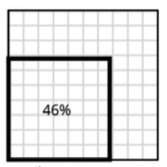

CAŃADA DE AGRA

Espacio libre de uso público

FIGURA 4 | Porcentajes de ocupación en pueblos de colonización

FUENTE: ELABORACIÓN PROPIA CON BASE EN DATOS EXTRAídOS DE CENTELLAS (2OIO) 
Los valores de ocupación del suelo que el programa de vivienda supondría respecto del total de la superficie del conjunto en los pueblos de colonización sería considerablemente inferior a las cifras que se analizaban para los poblados dirigidos, con valores medios cercanos al $10 \%$, una consecuencia obvia de no contar en el entorno rural con problemas de escasez de suelo. Esa situación permitía, a su vez, manejar cifras de ocupación de suelo libre de uso privado considerablemente mayores (valor medio superior al 20\%), ideales para conjuntos donde las viviendas requerirían de tales espacios para satisfacer las necesidades derivadas del trabajo en el campo.

La premisa de ejecutar conjuntos autosuficientes suponía, necesariamente, la consideración de equipamientos que, de alguna manera, hicieran posible esa condición autónoma. Con tal fin, el INC definió un programa de equipamientos muy completo para el desarrollo de este tipo de pueblos, el cual dependía del número de viviendas totales del conjunto, a su vez determinadas en relación con la superficie disponible de tierras aptas para el cultivo (Centellas, Ruiz \& García-Pellicer, 2009), pero que al menos en los casos de estudio referidos, Vegaviana y Cańada de Agra, no suponían mucho más del $2 \%$ de la ocupación de la extensión total de dichos pueblos. Como equipamiento mínimo se fijó la iglesia, con sacristía y despacho parroquial; un edificio administrativo, con una pequeńa oficina de correos, un juzgado, un dispensario, y viviendas para los funcionarios y el médico; un edificio social, con espacios de bar, cine, salón de baile, etcétera; escuelas, con viviendas para los maestros; y, finalmente, las artesanías y comercios que atendían las necesidades diarias de los colonos y trabajadores.

Los viarios en estos pueblos se clasifican, y jerarquizan, según las siguientes categorías: calles principales -es frecuente que una o dos vías principales, significadas por una mayor anchura y por la presencia de vegetación, atraviesen el asentamiento de un extremo al otro, así como el trazado de una vía perimetral de ronda, también de gran anchura-; calles secundarias y calles de carros (Oyón, 1985). Los pueblos de colonización presentan, además, una particularidad en sus trazados viarios, como consecuencia de su propia condición de ser asentamientos asociados al trabajo en el campo, que hace que, por temas meramente higienistas, pueda establecerse una nueva clasificación de estos conjuntos atendiendo a la separación o no de sus viarios (Herrero, 1948). Centellas (2010) señala cómo, de los 208 pueblos de colonización estudiados, más de la mitad (124 casos) tienen un esquema de calles mixtas, donde conviven a diario personas y animales; una minoría (21 casos) presenta separación parcial de usuarios en sus viarios; mientras que finalmente casi una tercera parte de ellos (63 casos) recurre a una total independencia de las circulaciones. Esta última modalidad da lugar a los trazados urbanísticos de mayor interés, al alejarse sobremanera de las rígidas directrices propugnadas desde el INC, en beneficio de una visión más paisajística -Fernández del Amo y de la Sota fueron los arquitectos del inc que más se acercarían a esta línea de esquemas más orgánicos-. Si se analizan los datos de ocupación de suelo en este último tipo de pueblos de colonización, y concretamente considerando los conjuntos de Vegaviana y Cañada de Agra, obtenemos un valor medio de ocupación del 17,15\% del suelo del asentamiento.

Las bajas cifras de densidad señaladas dan lugar a rangos de ocupación de suelo asignado a espacio libre de uso público con valores en torno al $50 \%$; es decir, que al 
menos la mitad de la superficie de este tipo de conjuntos se destinó a suelo libre de uso público. A pesar de las reticencias iniciales de arquitectos como Herrero (1948, p. 354), la plaza se posicionaría como el espacio libre por excelencia en los pueblos de colonización. Por lo general ocupa localizaciones centrales respecto de la trama urbana, mientras la agrupación en torno a ella de los edificios colectivos principales -iglesia, ayuntamiento y centro cívico- representa casi una constante básica urbana de estos conjuntos (Oyón, 1985; Centellas, Ruiz \& García-Pellicer, 2009). La plaza constituye así el foco central de donde parten, o se cruzan perpendicularmente, aquellas vías principales de las cuales antes se comentaba, configurando lo que Oyón (1985) define como el "auténtico corazón del pueblo" (p. 314).

\section{Instalaciones de veraneo para trabajadores en la orilla litoral:}

las "ciudades de vacaciones"

La finalidad de la Sección de Albergues y Residencias del Departamento de Viajes, Vacaciones y Excursiones de la Obra Sindical de Educación y Descanso (OSED) era proporcionar alojamiento temporal a la clase obrera del país, para que pudiese así disfrutar de sus días de vacaciones, a un precio reducido y en lugares de gran atractivo natural y paisajístico -en zonas de playa, montańa, e incluso de interior, siempre y cuando existiese cierta riqueza cultural y artística en este último caso-. Para tal fin, se creó una multitud de instalaciones de veraneo a lo largo y ancho de la geografía espańola, de cuya ejecución material se hizo cargo generalmente la Obra Sindical del Hogar. Ellas supondrían un verdadero atractivo para el trabajador, quien podría disfrutar durante una quincena de un alojamiento particular en la playa, para él y su familia, sin que eso supusiera mella alguna en su pobre economía (Díaz Bello, 2001, p. 248).

En un primer momento, la OSED importó a España un modelo equivalente al de los edificios de residencias marinas y estaciones balnearias ensayados en el litoral italiano y el alemán, respectivamente (Díaz Bello, 2001; Jiménez Martínez, 2014; Muñiz, 1999, 2001a y 2001b). Es, sin embargo, al empeño personal de quien fuese Delegado Nacional de Sindicatos entre los años 1951 y 1957, José Solís Ruiz, que debemos la idea de implementar el novedoso modelo de las ciudades de vacaciones de Educación y Descanso que son objeto de estudio en este trabajo. Así, después de salpicar el territorio nacional con la construcción de multitud de residencias de veraneo para productores, la OSED decidió dar un salto cualitativo a sus asentamientos vacacionales, acometiendo la construcción de las ciudades de vacaciones de Educación y Descanso. Finalmente, tres serían los asentamientos de estas características que, en la segunda mitad del siglo xx, Educación y Descanso ejecutaría ex nibilo en diferentes puntos del litoral español: la Costa Dorada de Tarragona (figura 5), la Costa del Sol de Marbella y la Costa Verde Cantábrica de Perlora, Oviedo (Carcelén, 2017).

La primera de las tres ciudades de vacaciones de Educación y Descanso en ejecutarse en España, y que sirvió como modelo a efectos de programa y organización en el territorio, fue la Ciudad Residencial de Tarragona (figura 5), construida en tiempo récord entre los años 1955 y 1957, según diseńo de los arquitectos Antoni Pujol Sevil y Josep María Monravà López. Posteriormente, en el año 1956, siguieron su 
estela la Ciudad Residencial de Perlora y la Ciudad Sindical de Marbella (figura 6), cuya ejecución se dilató más en el tiempo.

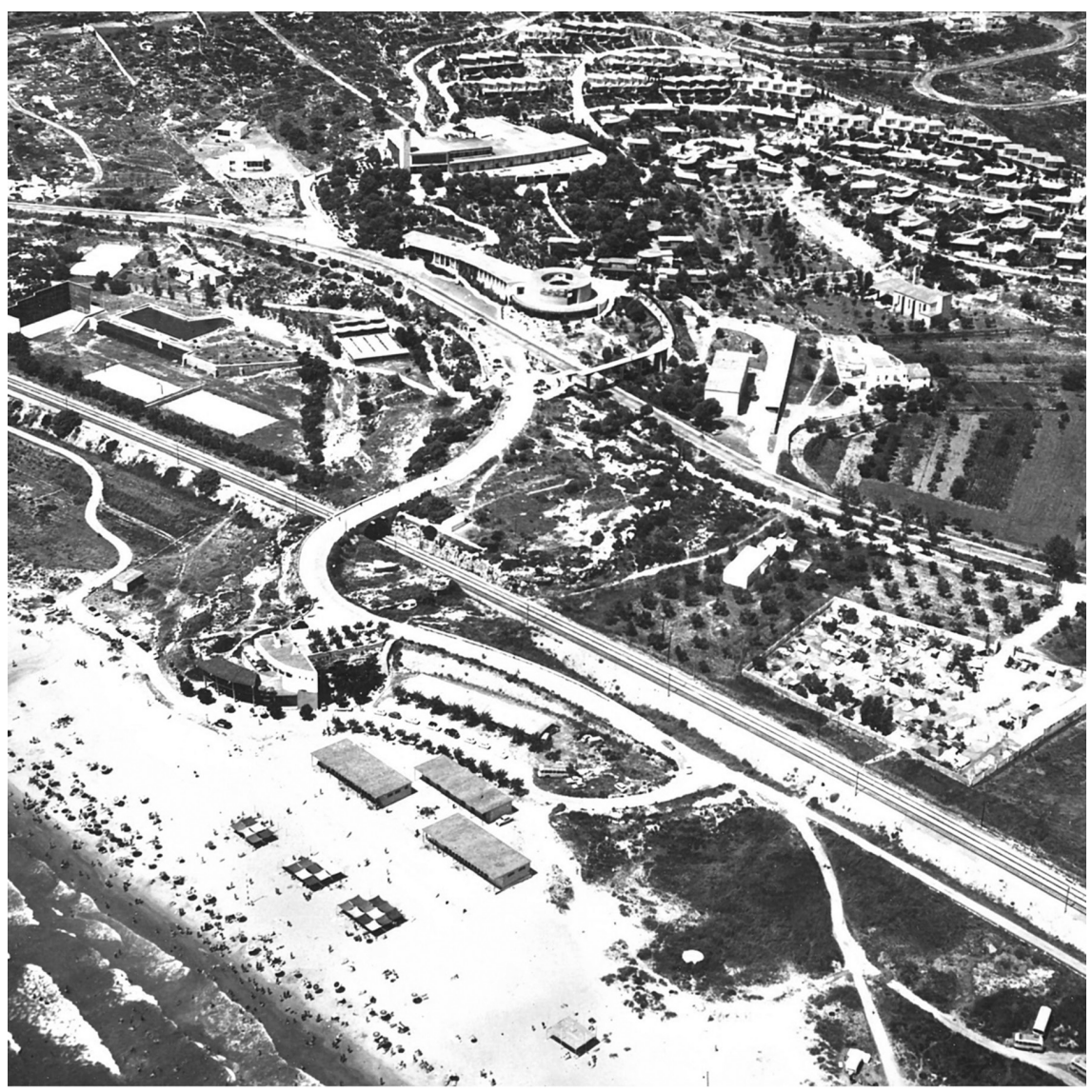

Figura 5 | Ciudad Residencial de Tarragona

FUENTE: ARCHIVO GENERAL DE LA ADMINISTRACIÓN, F/33-04445-O3

Como ya se hiciera con los dos modelos anteriores, enunciamos ahora los valores que se han obtenido al analizar las tres ciudades de vacaciones de Educación y Descanso (figura 7). El valor medio de densidad que se obtiene resulta algo inferior a 10 viv/ha (Tarragona, 13,5 viv/ha; Perlora, 7,88 viv/ha; Marbella 7,3 viv/ha), cifra muy por debajo del valor obtenido para los poblados dirigidos, que superaban ampliamente las 100 viv/ha, y sin embargo cercanos a la cifra señalada para los pueblos de colonización.

Esa baja densidad se traslada también a los datos de viviendas en estos conjuntos, que apenas supera el $5 \%$ de la ocupación de la superficie total de los asentamientos (Tarragona y Perlora comparten un 5,7\%, y Marbella presenta un 3,8\%). Ese reducido valor es consecuencia de un modelo residencial integrado por viviendas mínimas que, según Morales (1982), se ajustaban a "principios comunes en su 
composición, alojar a una sola familia y economía de espacios con gran aprovechamiento de los mismos" (pp. 46-47). A ello ańadía que, "dada su finalidad de descanso y vacaciones, la distribución interior se habría realizado para que solo sirvieran para dormir y estar, ya que las comidas habrían de hacerse en el restaurante colectivo". Esta condición se extendería al programa habitual en las viviendas de las tres ciudades de vacaciones de Educación y Descanso ejecutadas en la década de los años cincuenta. Así, como norma general, las viviendas de estos conjuntos no incorporan cocinas, y en contadas ocasiones integran pequeños espacios destinados a oficios, obligando en todo caso a los residentes a escapar de la intimidad de los apartamentos para tener que mezclarse con el grupo en el edificio de relación y comedor colectivo. Con idéntico objetivo, los espacios destinados a estar en los apartamentos se reducen a la mínima superficie posible. Los dormitorios se ciñen a poco más del espacio requerido para alojar las camas y un pequeño paso. Todas estas características dan lugar a un modo de habitar específico en este tipo de ciudades, que nada tendrá que ver con el de otros modelos de organización de la clase obrera en los que las viviendas reproducen esquemas y programas tradicionales. Si nos ceńimos al espacio libre de uso privado -aquel que, estando libre de edificación, se encuentra sin embargo asociado a una vivienda a modo de patio-, tenemos valores medios superiores al $10 \%$ para los poblados dirigidos y al $20 \%$ para los poblados de colonización; y, sin embargo, por debajo del 1\% en las ciudades de vacaciones de Educación y Descanso, siendo apenas significante el dato en el conjunto de Marbella, donde la figura del patio adquiere cierta importancia.

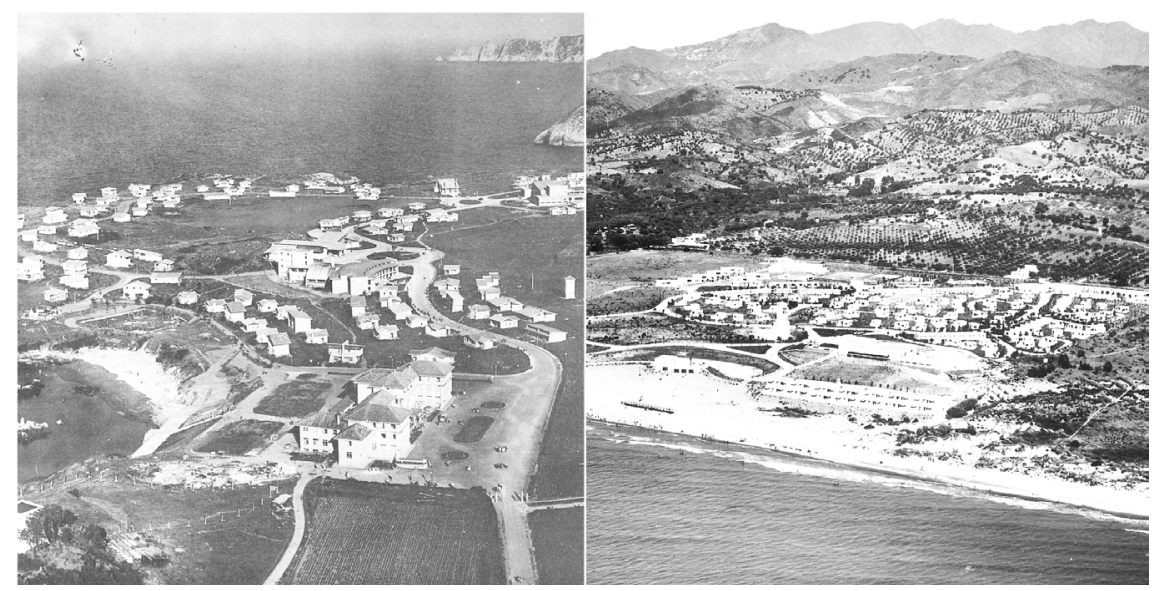

Figura 6 | Ciudad Residencial de Perlora (izq.) y Ciudad Sindical de Marbella (der.) FUENTE: ARCHIVO GENERAL DE LA ADMINISTRACIÓN, F/33-04592-I I, F/33-04564-07

La construcción del programa de equipamiento colectivo resultaba un factor irrenunciable ante la condición de autonomía que a estos conjuntos se les presumía. En los conjuntos de Educación y Descanso se repetirá en todos los casos, sin excepción, el mismo programa: edificios de recepción, comedores, iglesias, edificios de dirección y administración, centros médicos o enfermerías, tiendas o galerías 
comerciales y edificios destinados a garaje-taller, principalmente. Casi con toda seguridad, podría atribuirse esta característica a un proceso de imitación. Así, una vez definido el programa de equipamientos en la propuesta elaborada por Monravà y Pujol para Tarragona, se utilizaría este como referencia, tanto en la redacción de las bases del concurso de arquitectura a partir de las cuales se originaría el diseño construido finalmente en Marbella, como en la elaboración del programa colectivo del conjunto de Perlora, donde la única licencia que sobre el estándar definido se permiten los arquitectos redactores del proyecto será la duplicidad de comedores, justificado en cualquier caso ante la considerable extensión de dicha ciudad de vacaciones frente al resto. La importancia del equipamiento colectivo en estos conjuntos no queda representada por su valor de ocupación (valor medio inferior al 4\%), sino cuando hablamos en términos de superficie construida, con un valor para los equipamientos que en casi todos los casos supera al de las viviendas.

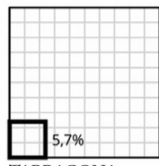

TARRAGONA
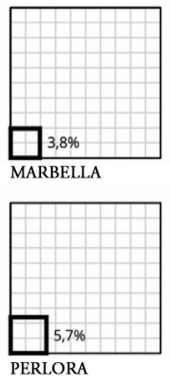

Viviendas
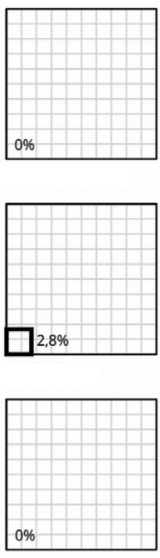

Espacio libre de uso privado
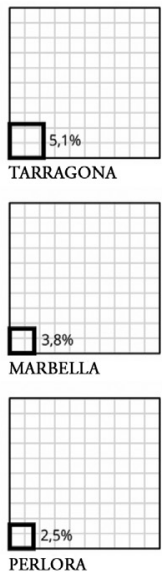

Equipamientos
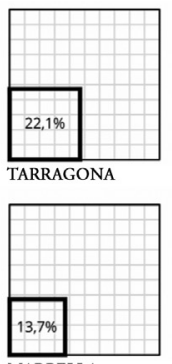

MARBELLA

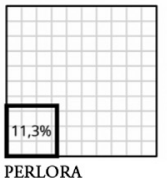

Viario

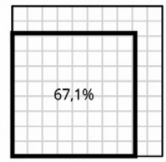

TARRAGONA

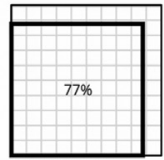

MARBELLA

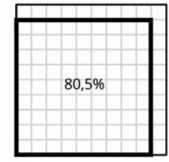

PERLORA

Espacio libre de uso público

FIGURA 7 | Porcentajes de ocupación en ciudades de vacaciones de Educación y Descanso

FUENTE: ELABORACIÓN PROPIA CON BASE EN DATOS EXTRAÍDOS DE CARCELÉN (2OI7)

A pesar de la unanimidad mostrada en los trazados viarios, con diseño de tipo orgánico en los tres casos, la repercusión que tendrá sobre el total de la superficie ocupada por las ciudades de vacaciones de Educación y Descanso no será homogénea, quedando en todo caso a expensas de las condiciones naturales de la orografía del terreno. Este hecho es el que da lugar a que, en Tarragona, que presenta el mayor desnivel de las tres ciudades de vacaciones ejecutadas, el viario represente más de la quinta parte de la superficie total de la parcela $(22,1 \%)$, mientras que en Perlora no tendrá mayor repercusión (5,7\%). Salvando estas distancias, el estudio global de las tres ciudades indicaría un valor medio de ocupación del viario de algo más del 15\% de la superficie total, un dato que se encuentra a mitad de camino entre los valores obtenidos para los otros modelos alternativos de organización de las clases obreras en España. 
El vacío, así como su uso, representa una de las grandes señas de identidad de las ciudades de vacaciones de Educación y Descanso con respecto a modelos organizativos no vacacionales en la Espańa de los ańos cincuenta. El hecho de que en la promoción de dichos conjuntos no interfirieran intereses de tipo especulativo fue, sin duda, determinante en este asunto. Así, en las ciudades de vacaciones ejecutadas se dan valores superiores a 200 metros cuadrados de suelo libre, de vacío, por cada residente, exceptuando Tarragona, en la que el valor es algo inferior a consecuencia de la repercusión del viario. Atendiendo ahora a los valores de suelo libre de uso público, mientras en los modelos alternativos el valor medio de este parámetro nunca superará el $50 \%$ de la superficie total de los asentamientos, en el caso de las ciudades de vacaciones de Educación y Descanso encontramos valores muy cercanos al $75 \%$, lo que supone que al menos las tres cuartas partes de su superficie se destinaba a este tipo de uso del suelo.

\section{Análisis comparativo de modelos}

Una vez estudiados los tres modelos de organización de las clases obreras en el territorio objeto de este trabajo, se entiende el origen de las considerables diferencias entre densidades de cada uno de ellos (figura 8), especialmente entre los altos valores obtenidos para los poblados dirigidos frente a los otros dos modelos, que presentan valores bajos más próximos. En las periferias de la ciudad industrial, la urgente necesidad de construir poblados para proporcionar alojamiento al mayor número posible de trabajadores, sumada a la escasez de suelo para la ejecución de dichos poblados, hacía imposible recurrir a esquemas de menor compacidad. De hecho, el empleo de viviendas unifamiliares en estos conjuntos (algo a todas luces contradictorio con el objetivo real de este modelo), no obedecería en realidad al propósito de lograr un incremento de la calidad de vida de sus moradores, sino más bien a la necesidad (o imposición) de incorporar la autoconstrucción en la ejecución de los poblados dirigidos. Así, no pudiendo confiar la construcción de bloques altos a una mano de obra sin cualificar -salvo temibles excepciones, como la del poblado de Canillas, donde el arquitecto Luis Cubillo relata cómo la mano de obra no especializada, a la que coloquialmente se referían como "domingueros", también participaba en la construcción de los bloques en altura, afortunadamente sin incidentes de gravedad (Esteban, 1999)-, surgiría el esquema mixto al que ya hicimos referencia. En los pueblos de colonización, sin embargo, la escasez de suelo dejaría de ser un inconveniente, al contarse con la extensa llanura del campo español, mientras que en las ciudades de vacaciones de Educación y Descanso la baja densidad sí se utilizaría en beneficio del bienestar de los trabajadores que, con carácter temporal, residían en ellas. 


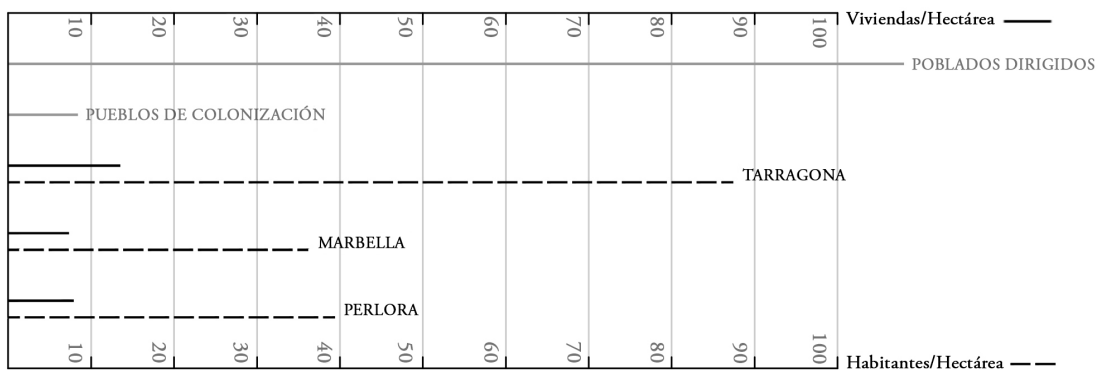

FIGURA 8 | Representación gráfica comparativa de densidades

FUENTE: CARCELÉN (2017)

A continuación se muestran las gráficas comparativas que posibilitan conocer las diferencias de planteamiento frente a cada uno de los parámetros cuantitativos estudiados para cada uno de los modelos organizativos de este trabajo (figura 9).
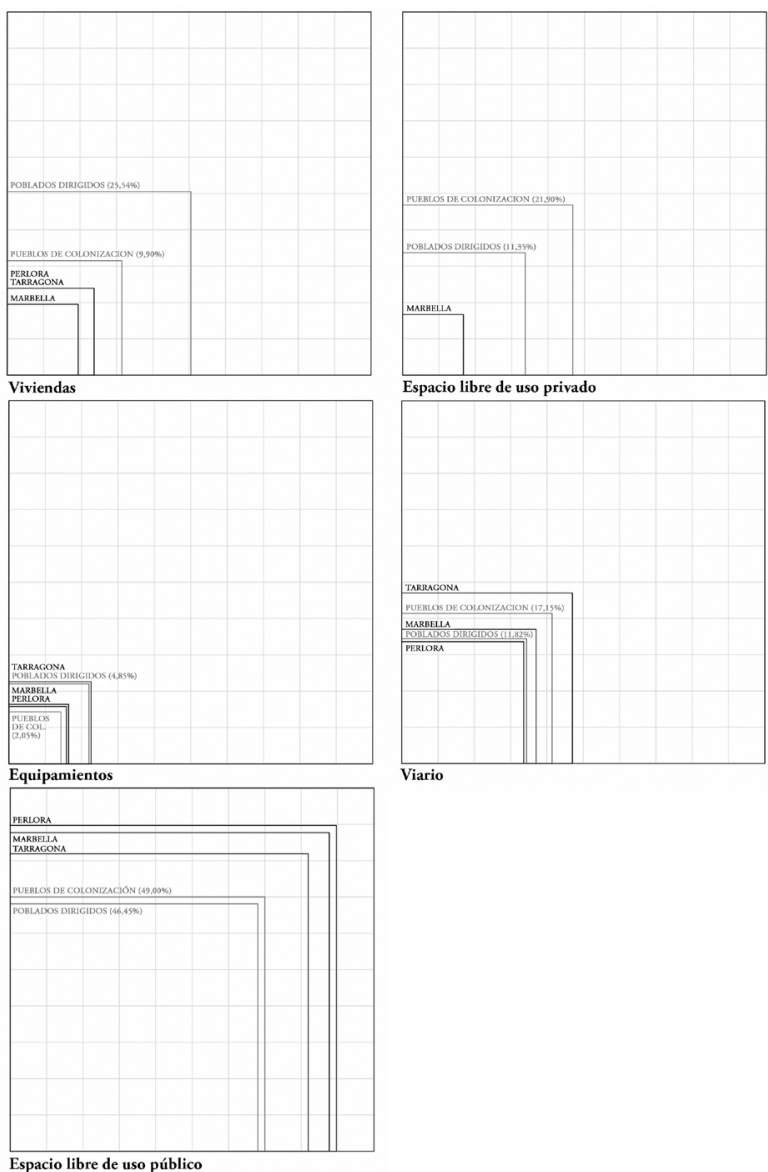

Viario

FIGURA 9 | Representación gráfica comparativa de parámetros urbanos FUENTE: CARCELÉN (2OI7) 
De la misma manera que ocurre respecto de los niveles de densidad, también fue en la periferia industrial donde mayor ocupación del territorio supondrían las viviendas, con cifras considerablemente superiores a las de los pueblos de colonización o las ciudades de vacaciones, que presentan nuevamente los valores más bajos, como consecuencia de aplicar esquemas de vivienda mínima frente a los de vivienda tradicional empleados en el resto de los modelos. Sin embargo, la tendencia cambia cuando se analiza el suelo libre de uso privado, donde los pueblos de colonización destacan por la importancia de los grandes patios de trabajo propios de este modelo. En las ciudades de vacaciones -como ya se señaló-, este tipo de suelo es prácticamente inexistente, como consecuencia directa de una estrategia de no parcelación en los conjuntos de Educación y Descanso, que propiciaría la permeabilidad y libertad de recorridos hacia la playa, siguiendo criterios de "mínima subdivisión del territorio", según los términos de Sauquet (2012, p. 112).

Los valores de ocupación han demostrado no ser muy clarificadores, al menos en lo que se refiere a la repercusión del equipamiento colectivo en el asentamiento. Así, pese a mostrar valores ciertamente bajos y próximos en cualquiera de los tres modelos, su presencia en cada uno de ellos no ha tenido la misma importancia, yendo esta cuestión en ascenso conforme aumentaba la demanda de autonomía de los conjuntos. Mientras en los poblados obreros de la periferia industrial existía una fuerte carencia de equipamiento de reunión, como centros sociales, centros de juventud, etcétera, los pueblos de colonización sorteaban este problema con la construcción de dichos equipamientos. Especial importancia tendrá la construcción de equipamientos en las ciudades de vacaciones de Educación y Descanso, donde se priorizarán los espacios de relación y reunión de los trabajadores, promocionando la cuestión colectiva por encima de la individual, como demuestran las cifras de superficies construidas desveladas en este trabajo.

El viario no resulta un parámetro diferenciador en ninguno de los tres modelos estudiados, más allá del propio diseño, con valores medios de ocupación cercanos al $15 \%$ en todos los casos. Solo algunos casos específicos se vieron penalizados a consecuencia de la duplicación de caminos que supuso la separación de viarios atendiendo a las cuestiones funcionales.

Finalmente, los datos de ocupación de suelo libre de uso público sí resultan un factor diferenciador entre los distintos conjuntos, con los mayores valores obtenidos en las ciudades de vacaciones de Educación y Descanso, en parte por el anhelo de una implantación respetuosa en los privilegiados emplazamientos donde habrían de ejecutarse, en parte por la prevalencia de lo colectivo sobre lo individual que ya apuntamos.

\section{Conclusiones}

El periodo de posguerra representó una fase de experimentación sin precedentes para los arquitectos espańoles, quienes tuvieron que hacer frente y dar respuesta arquitectónica y urbanística a nuevas problemáticas, como la ordenación de la clase obrera en el territorio en los diferentes contextos señalados en este trabajo. Si bien, como ha quedado patente, el corpus teórico es fértil en lo que se refiere a los poblados obreros en la periferia de la ciudad industrial y a los pueblos de colonización en el 
entorno rural, no lo resulta tanto cuando nos referimos a la ocupación de la orilla litoral. Este trabajo se ha propuesto poner de manifiesto la relevancia de un tercer modelo organizativo de las clases obreras en el territorio, más desconocido: el de las ciudades de vacaciones promovidas por Educación y Descanso, que surgiría para dar respuesta a una demanda incipiente en el periodo de estudio, como fue la organización del reposo obrero.

Pese al desconocimiento señalado, la construcción en la década de los años cincuenta de tres de estas ciudades de vacaciones, en Tarragona, Marbella y Perlora, ha propiciado su estudio y análisis cuantitativo en los mismos términos que reconocidos investigadores hicieran en las últimas décadas con los poblados dirigidos o los pueblos de colonización. También ha llevado a la elaboración de un análisis comparativo de estos tres modelos de organización contemporáneos, que ha permitido poner en contexto unas ciudades de vacaciones ciertamente ignoradas, más allá de escasos trabajos e investigaciones en el campo de la historia de la arquitectura.

De dicho análisis se desprende un conjunto de aspectos formales casi específicos de estos asentamientos ideados para el reposo obrero. Es necesario tomar en cuenta, sin embargo, que en todos los casos de estudio del trabajo, en los tres modelos, sus aspectos formales estuvieron influidos por factores externos y ajenos a los arquitectos proyectistas. Entre dichos factores puede contarse:

a. la disposición de suelo, con una evidente escasez del mismo en la periferia de la ciudad industrial frente a la llanura rural o la orilla litoral, que repercutirá en parámetros como la densidad, por una parte;

b. la urgencia de producir alojamiento, extrema en el caso de los poblados dirigidos, que debían dar cobijo a la inmigración masiva, y acusada en los pueblos de colonización del campo español, determinante en todo caso en la repercusión del programa de viviendas;

c. el propio destino del modelo, factor decisivo en lo que a espacios libres de uso privado y público se refiere;

d. o, incluso, el factor de temporalidad, un parámetro que resulta inherente a las ciudades de vacaciones de Educación y Descanso.

En el último de los casos señalados, el de las ciudades de vacaciones -de particular interés en este trabajo-, los factores identificados nos sitúan ante un modelo organizativo que, frente a sus coetáneos, se caracterizará por los siguientes atributos: i) la bajísima densidad y la ausencia de edificación en altura, cuestión decisiva para lograr la deseada integración paisajística de las ciudades de vacaciones en un litoral en estado casi virginal previo a la inminente depredación que el turismo masivo provocará en las décadas posteriores; ii) la predominancia del suelo libre de uso público, respecto al casi inexistente suelo libre de uso privado, con el fin de propiciar las anheladas relaciones sociales entre sus habitantes y la libertad de recorridos entre edificaciones -solo posible por la inexistencia de la propiedad privada en dicho modelo-; y iii) la primacía de los equipamientos públicos frente a las viviendas, de nuevo para favorecer la colectividad por sobre el espacio individual, y que dará lugar a un programa mínimo de vivienda donde los espacios de estancia se reducirán a la mínima expresión. 


\section{Referencias bibliográficas}

Carcelén González, R. (2017). Cuando la clase obrera se hizo turista. Las ciudades de vacaciones de la Obra Sindical de Educación y Descanso. Estudio de un modelo inacabado 19551975. (Tesis Doctoral). Universidad Politécnica de Cartagena. http://dx.doi. org/10.31428/10317/6031

Centellas Soler, M., Ruiz García, A. y García-Pellicer López, P. (2009). Los pueblos de colonización en Almería. Arquitectura y desarrollo para una nueva agricultura. Almería: Colegio Oficial de Arquitectos de Almería, Instituto de Estudios Almerienses, Fundación Cajamar.

Centellas Soler, M. (2010). Los pueblos de colonización de Fernández del Amo. Arte, arquitectura y urbanismo. Barcelona: Fundación Caja de Arquitectos.

Díaz Bello, M. (2001). En busca del obrero: la organización del consentimiento en la España franquista. En M. A. Ruiz Carnicer \& C. Frías Corredor (coords.), Nuevas tendencias historiográficas e historia local en España. Actas del II Congreso de Historia Local de Aragón (pp. 241-253). Huesca, 7-9 julio (actas impresas).

Esteban Maluenda, A. M. (1999). La vivienda social espańola en la década de los 50: un paseo por los poblados dirigidos de Madrid. Cuaderno de Notas (7), 55-80. http://oa.upm. es/6561/

Fernández-Galiano, L. (1989). Madrid 1956. La historia de los poblados. En L. A. FernándezGaliano, J. F. Isasi \& A. Lopera, La quimera moderna. Los poblados dirigidos de Madrid en la arquitectura de los 50 (pp. 9-50). Madrid: Hermann Blume.

Fernández-Galiano, L., Isasi, J. F. y Lopera, A. (1989). La quimera moderna. Los poblados dirigidos de Madrid en la arquitectura de los 50. Madrid: Hermann Blume.

Guerrero Fernández, J. (2016). Ciudad Residencial de Educación y Descanso de Tarragona: 1954-1959. La organización del ocio obrero en la posguerra española (Tesis de Máster). Universitat Politècnica de Catalunya. https://bit.ly/2ZtcEf3

Guillem González-Blanch, M. P. (2014). Manifiesto moderno construido: poblados dirigidos. En I Congreso Pioneros de la Arquitectura Moderna Española (pp. 404-410). Madrid (Actas digitales). https://dialnet.unirioja.es/servlet/articulo?codigo=5599703

Herrero, A. (1948). Independencia de circulaciones y trazado de poblados. Revista Nacional de Arquitectura (80-81), 348-358. https://bit.ly/2XJZSXL

Isasi, J. F. (1989). Los poblados en el urbanismo y la vivienda de posguerra. En L. A FernándezGaliano, J. F. Isasi \& A. Lopera, La quimera moderna. Los poblados dirigidos de Madrid en la arquitectura de los 50 (pp. 95-132). Madrid: Hermann Blume.

Jiménez Martínez, L. (2014). La construcción política del turismo durante el franquismo: el discurso turístico como recurso (1956-1975). En Jornades d'Història Econòmica del Turisme. La mediterrània molt més que sol i platja (1900- 2010), Menorca, 26-27 septiembre (actas digitales). http://www.ime.cat/contingut.aspx?idpub=9561

López Díaz, J. (2002). La vivienda social en Madrid 1939-1959. Espacio, Tiempo y Forma, Serie vII, Historia del arte (15), 297-338. http://revistas.uned.es/index.php/ETFVII/ article/view/2401/2274

Morales Folguera, J. M. (1982). La arquitectura del ocio en la Costa del Sol. Marbella, Málaga: Universidad de Málaga. Servicio de Publicaciones e Intercambio Científico. 
Moya González, L. (1976). Los barrios de promoción oficial de Madrid (Tesis doctoral). Escuela Técnica Superior de Arquitectura, Universidad Politécnica de Madrid.

Moya González, L. (1983). Barrios de promoción oficial. Madrid 1939-1976. La politica de promoción pública de vivienda. Madrid: Colegio Oficial de Arquitectos de Madrid.

Moya González, L (1997). La realidad de la vivienda obrera. Poblados de absorción, mínimos y dirigidos, y Unidades Vecinales de Absorción (U.V.A.s). En La vivienda experimental: concurso de viviendas experimentales de 1956 (pp. 81-91). Madrid: Fundación Cultural COAM. http://oa.upm.es/10892/

Muñiz Aguilar, D. (1999). La política de Turismo Socialen España (Tesis doctoral). Departamento de Economía Aplicada, Facultad de Ciencias Económicas y Empresariales, Universidad de Málaga. http://www.biblioteca.uma.es/bbldoc/tesisuma/16276814.pdf

Muñiz Aguilar, D. (2001a). Evolución histórica de la política de Turismo Social española. En Estudios Turísticos (147), 141-156. http://estadisticas.tourspain.es/img-iet/revistas/ret147-2001-pag141-156-86371.pdf

Muñiz Aguilar, D. (2001b). La política de Turismo Social. Málaga: Consejería de Turismo y Deporte, Junta de Andalucía. http://www.juntadeandalucia.es/ turismocomercioydeporte/publicaciones/4323.pdf

Oyón Bañales, J. L. (1985). Colonias agrícolas y poblados de colonización. Arquitectura y vivienda rural en España (1850-1965). (Tesis doctoral). Universitat Politècnica de Catalunya. http://hdl.handle.net/10803/5863

Oyón Bañales, J. L. (2002). Historia urbana e historia obrera: reflexiones sobre la vida obrera y su inscripción en el espacio urbano, 1900-1950. Historia Contemporánea (24), 11-58. https://upcommons.upc.edu/handle/2099/695

Rabasco Pozuelo, P. (2009). La imposibilidad de lo vernáculo. La arquitectura del INc. Átrio. Revista de Historia del Arte (13), 73-84. https://bit.ly/2IVr8yq

Sambricio, C. (1999). La vivienda en Madrid, de 1939 al Plan de Vivienda Social, en 1959. En su La vivienda en Madrid en la década de los cincuenta: el Plan de Urgencia Social (pp. 13-84). Madrid: Electa. http://oa.upm.es/1583/

Sambricio, C. (2003). Un siglo de vivienda social 1903-2003. Madrid: Ministerio de Fomento.

Sanz Díaz, D. (2001). La ciudad residencial de Perlora: espacio de ambigüedad territorial, social, ideológica y constructiva. En Congreso Dos Décadas de Cultura Artística en el Franquismo (1936-1956). Granada (Actas digitales), 689-701.

Sauquet Llonch, R. (2012). La Ciutat de Repòs i Vacances del Gatcpac (1931-1938). Un paisatge pel descans. Departament de Projectes Arquitectònics. Universitat Politècnica de Catalunya. https://upcommons.upc.edu/handle/2117/95014

Tamés Alarcón, J. (1948). Proceso urbanístico de nuestra colonización interior. Revista Nacional de Arquitectura (83), 413-424. https://bit.ly/2L47DX1

Tatjer, M. (2005). La vivienda obrera en España de los siglos XIX y xx: de la promoción privada a la promoción pública (1853-1975). Scripta Nova, revista electrónica de geografía y ciencias sociales, 9 (194). http://www.ub.edu/geocrit/sn/sn-194-23.htm

Tomillo Castillo, A. (2014). La dialéctica entre progreso y desarrollo en la arquitectura moderna española: el caso de las ciudades sindicales y el tiempo funcional. En I Congreso Pioneros de la Arquitectura Moderna Española. Madrid (Actas digitales), 964-974. https:// dialnet.unirioja.es/servlet/libro?codigo $=656127$ 